\title{
1. Size and local democracy
}

\section{INTRODUCTION}

How large should local governments be? This question has exercised the minds of scholars and public sector reformers alike from antiquity to the present. In the years since the end of World War II, the question has once again been high on the agenda in many contemporary democracies, and many countries have implemented local government reforms resulting in more or less substantial changes in the population size of local government units. In some countries these changes have moved in the direction of reducing the size of local units while elsewhere the winds of change have been blowing from another quarter (see Baldersheim \& Rose 2010b; Martins 1995; Rose 2005b). ${ }^{1}$ In the Netherlands, for example, as a result of a large number of successive small-scale regional amalgamation reforms, the number of municipalities has been gradually reduced over the last sixty years, from 1,015 in 1950 to 458 in 2006 (Boedeltje \& Denters 2010). In combination with the growth of the Dutch population, these reforms have resulted in a marked increase in the size of the Dutch municipalities. Whereas the average population size of a Dutch municipality in 1950 was almost 9,900, in 2006 the average size was over 35,600 residents (Denters \& Klok 2005).

Norway has also undergone a transformation of the municipal landscape, although the changes were implemented over a shorter period of time and were less drastic than in the Dutch case. Following a protracted period of investigation and public debate, the Norwegian parliament passed an act in the mid-1950s that opened the way for a process of amalgamation which, in the course of the following ten-year period, reduced the number of municipalities from 744 to 443 (Baldersheim \&

\footnotetext{
1 In some of the new democracies in Eastern Europe such as Hungary and the Czech and Slovak republics, 'the predominant tendency has been one of division and fragmentation rather than amalgamation and consolidation' (Rose 2005b: 401). This tendency is to be seen against the backdrop of previous forced amalgamations that took place under the old Communist regimes in Central and Eastern Europe (see Illner 2010; Swianiewicz 2010; and articles in Local Government Studies, 36(2), 2010).
} 
Rose 2010d; Rose 1996). Also here the result was a pronounced increase in the size of municipalities. In 1951 only 19 per cent of all municipalities had more than 5,000 inhabitants, whereas the comparable figure in 1974 was 45 per cent. The consequences for population distribution were equally striking: the percentage of the population living in municipalities with more than 5,000 inhabitants rose from 51 per cent in 1951 to 84 per cent in 1974.

Amalgamation reforms have likewise transformed Danish local government. But rather than using an incremental approach as the Dutch have, the Danes have opted for more comprehensive, nationwide amalgamations, much as the Norwegians. Thus, in a major reform wave implemented in 1970, the number of municipalities was reduced from 1,064 to 277 and later to 275 (Albæk 1996: 23). Then, in a more recent reform, the number of municipalities was reduced still further in 2007 to a mere 98. The result of this last amalgamation reform was a substantial increase in the average population size, increasing it from 19,900 in 2005 to 55,200 in 2007 (Mouritzen 2010; Rose 2005b: 409-12). ${ }^{2}$

In other countries, by comparison, national as well as local governments have been much more reluctant to engage in territorial reforms of local government. In Switzerland, for instance, the number as well as the size of municipalities has been quite stable over time. Close to 3,100 municipalities existed in 1950 and this figure had only dropped to 2,758 as of 2007, at which time the average population size was around 2,700 inhabitants (Baldersheim \& Rose 2010b: 3, Table 1.1).

Territorial reforms are typically accompanied by heated debates about the desirability of small- versus large-scale local government units. Such debates are by no means new. Long ago Aristotle, in his famous treatise 'The Politics', considered the effects of size on the quality of governance. On the one hand Aristotle held the view that a viable polis should be a self-sufficient and autonomous unit large enough to provide its citizens with the goods and services they need and demand. On the other hand he also thought that a polis should be small enough to permit responsible citizenship. This implied that citizens should be in a position to assess the competence and the performance of the governors in order to distribute public offices according to merit. His fear was that in large polities citizens might be unable to acquire adequate knowledge to select and control their governors in a responsible manner. On this basis Aristotle pointed to an inherent tension between two basic concerns: '[a] state

2 Rose (2005b) also provides a more extensive overview of recent territorial and functional reforms in European local government systems. 
when composed of too few is not, as the state ought to be, self-sufficient; when of too many, though self-sufficient in all mere necessaries, as a nation may be, it is not a state, being almost incapable of constitutional government' (Aristotle 1984: 2105).

Two observations can be made in comparing Aristotle's statement with current debates. First, as with Aristotle's arguments, contemporary debates are essentially framed in terms of two sets of normative criteria. One set is substantive: the function of political authorities is to secure the goods and services the public wants. Self-sufficiency, according to Aristotle, was the main functional requirement to be met by a political authority. The second set is procedural: here the main requirement, in Aristotle's view, was that people should be in a position to assess the competence and the performance of their governors.

These substantive and procedural concerns reappear in contemporary debates about the democratic effects of local government reforms. Dahl and Tufte, in their widely cited work Size and Democracy (1973), for example, analyse the effects of variations in the population size of governments on the basis of two basic dimensions - system capacity and citizen effectiveness, respectively. System capacity refers to the requirement that a system should 'have the capacity to respond fully to the collective preferences of its citizens' - a substantive concern, whereas citizen effectiveness refers to the extent to which citizens 'acting responsibly and competently fully control the decisions of the polity' - a procedural concern (Dahl \& Tufte 1973: 20). Thirty years after Dahl and Tufte, in a volume entitled Reforming Local Government in Europe: Closing the Gap between Democracy and Efficiency, Kersting and Vetter (2003) highlight the on-going relevance of these concerns for policy makers in many countries. The same is also evident in other discussions of what Scharpf (1999: 6-13) has referred to as 'two faces of democratic self-determination' - i.e. 'government for the people', a substantive preoccupation with finding effective solutions for collective problems, and 'government by the people', a procedural focus in which public participation is a mechanism for securing political decisions that reflect community preferences.

A second similarity between Aristotle's argument and current debates is the assumption that changes in the size of political units are likely to have effects on both the democratic quality and functional performance of governments, and that there may be a trade-off between substantive and procedural values. Indeed, on the basis of an extensive review of theoretical arguments and empirical evidence, Dahl and Tufte came to the (perhaps somewhat discouraging) conclusion that '[n]o single type or size of unit is optimal for achieving the twin goals of citizen effectiveness 
and system capacity' (Dahl \& Tufte 1973: 138). The smaller the polity's population size, the greater might be the citizen's effectiveness in influencing political decisions, but at the same time small polities may lack the problem-solving capacity needed to meet major community issues. On this basis Dahl and Tufte conclude that 'in the extreme case, a citizen could be maximally effective in a system of minimal capacity for dealing with major issues (e.g. international violence) or minimally effective in a system of maximal capacity for dealing with major issues' (Dahl \& Tufte 1973: 138).

In the light of considerations relating to these two dimensions Aristotle was somehow convinced that the optimum size would be 'easily ascertained by experience' (Aristotle 1984: 2105). Recent political debates about the merits of amalgamation reforms and the academic debate about the related questions 'Is small really so beautiful?' and 'Is big really so ugly?' (Newton 1982) belie such an optimistic belief. ${ }^{3}$ There are several reasons for this enduring debate. According to Keating (1995: 131) the main reason is that the concept of democracy and its different dimensions are politically contested. As a result, different people attach different weights to various criteria of democracy, leading to a situation in which, even if the actual empirical effects of size on the realization of relevant values were known, the optimum size might nonetheless differ for people with different value priorities.

Determining the optimum size, however, is also complicated by the lack of empirical evidence regarding the actual effects of size on relevant aspects of democratic governance. At the time Dahl and Tufte wrote Size and Democracy they noted that their research was seriously hampered by 'a lamentable paucity of data' (1973: 61). At the outset of the new millennium political science had not made much progress in establishing more conclusive evidence on the issue of size and democracy. Keating (1995: 131) argued that: '[t]his is partly for lack of data, partly because of difficulties in measurement'. Even though some national studies on aspects of the relation between size and a variety of different aspects of local democracy are available, ${ }^{4}$ the external validity of these studies is

3 Dahl's presidential address for the American Political Science Association might be considered as a starting point for the contemporary academic debate (Dahl 1967). In the years following, Dahl often returned to this topic (see Dahl 1994 and 1997 as well as Dahl \& Tufte 1973).

4 Among others, see e.g. Baldersheim et al. (2003); Bjørklund \& Sørensen (1990); Denters \& Geurts (1998a); Denters et al. (1990); Fletcher (1969); Hansen et al. (1987); Jamil (1991); Johansson et al. (2007); Kaniovski \& Mueller (2006); Kjær \& Mouritzen (2003); Ladner \& Bühlmann (2007); Mouritzen (1989); 
typically limited, both in terms of the dimensions of local democracy considered and in terms of the peculiarities of national systems of local government that have been examined.

In this book we make an effort to fill this lacuna in our comparative empirical knowledge. Our central research question is what is the effect of size on the democratic quality of municipal government? Size, of course, has many different dimensions: population size, geographic area, density and the size of the jurisdiction's economy, to mention but a few (cf. Dahl \& Tufte 1973: 17-20). Contemporary political and academic debates about the democratic effects of the scale of local government, however, relate almost exclusively to population size. In this book we follow this tradition, concentrating our attention on the effects of the population size of municipalities for the quality of local democracy. We seek to answer our research question on the basis of empirical analyses of conditions existing in 234 municipalities found in four countries Switzerland, Norway, Denmark and the Netherlands. ${ }^{5}$ To do so requires first that we provide a more precise definition of the aspects of democratic government on which we focus our analyses, and second that we clarify how these aspects may be related to size. The remainder of this chapter is devoted to these tasks.

\section{DEMOCRATIC GOVERNMENT: DIMENSIONS AND EMPIRICAL MEASURES}

Although the debate about the effects of size involves both substantive criteria such as system capacity and procedural criteria such as citizen effectiveness, on normative grounds the procedural aspect of democracy is arguably more fundamental. To qualify as a democracy a political system has to allow its citizens effective control of its political agenda and the decisions rendered (government by the people). In short, even if a political system effectively and efficiently provides policies, services and facilities in perfect agreement with the needs and demands of its citizens (government for the people), such a system is not genuinely democratic if its citizens are excluded from the process of political

Newton (1982); Oliver (2000, 2001); Pettersen \& Rose (1996); Rallings \& Thrasher (1990, 1994).

5 This ordering of the four countries, which will be used systematically throughout the book, is simply based on the average size of the municipalities. An account of the local government systems in each of these countries is found in Chapter 3. 
decision making. Our primary concern in this book, therefore, is with citizen effectiveness, or the control dimension of government. ${ }^{6}$

As Weir and Beetham have put it, a system of collective decision making can be called democratic 'to the extent that it is subject to control by all members of the relevant association considered as equal' (Weir \& Beetham 1999: 8, emphases added). This formulation contains two important considerations: the existence of an association of which individuals are members, and the status ascribed to members. The former, the 'relevant association', refers to the definition of the 'demos' (Dahl 1970) or the relevant public (Dewey 1954). In the context of municipal politics, a pragmatic definition of the demos would be the adult population living within the local government's jurisdiction. In a democracy, moreover, the notion of citizen control goes hand-in-hand with the principle of equal membership status: all members of the demos should be in an equal position to control decisions and decision makers. Both considerations merit close investigation and analysis. In the present inquiry, however, for reasons of feasibility we set aside a systematic analysis of the effects of municipal size for the realization of political equality and rather concentrate our attention on the relevance of size for aspects relating to citizen control.

The principle of citizen control is applicable to both direct and indirect, representative democracy (Beetham 2004: 7). Direct democracy figures most prominently in Switzerland, but as will be seen in Chapter 3, local governments in all four countries studied in this book rely on the popular election of public officials as part of a democratic infrastructure aimed at securing citizen control. ${ }^{7}$ Weir and Beetham (1999) argue that in such a context the realization of the principle of control is dependent upon three intermediate principles. First, there is the principle of authorization. This principle involves what are largely constitutional provisions that provide public officials with the formal democratic legitimacy to exercise public powers on behalf of the population - for example laws that regulate the electoral procedures by which officials are elected and can be removed from office. This principle also implies a role for the

6 This also implies that we will not discuss the potential impact of the size of local government on the realization of liberal democratic principles of legal equality and legal security. For work that does include such an analysis see e.g. Denters et al. (1990).

7 Because of the special character of Swiss municipalities, where control is not limited to elections but includes also important political decisions, we discuss the democratic effects of size in the context of direct democratic systems in Switzerland in Chapter 12. 
public in the approval of basic constitutional provisions and their revision. From a comparative perspective, the principles of authorization are typically determined at the supra-local level, either by the national government (in unitary states) or by the state or cantonal government (in federal systems).

Second, there is the principle of accountability. This principle refers to the accountability of public officials to the public. ${ }^{8}$ In representative democracy the main mechanism securing this principle is that of free, competitive elections where all adult citizens can exercise control over the political fate of political officeholders. Third, there is the principle of responsiveness which requires that the government systematically takes note of the full range of public opinion in the formulation and implementation of law and policy (Beetham \& Stoker 1996: 32). This principle requires a well-functioning system of political representation in which elected representatives are open and accessible to public demands, and are also prepared to act upon citizen demands.

Both accountability and responsiveness depend upon an open flow of information. In the first instance accountability depends upon the supply of information about officeholders and their actions to the public. This information is crucial if citizens are to exercise effective electoral control in the case of inadequate performance or misconduct. Responsiveness, on the other hand, depends on the supply of information about citizens' needs and preferences to politicians. This is crucial if the public's will is to guide a polity's authoritative decisions.

In facilitating both flows of information, widespread political engagement plays a vital role. First and foremost, this implies the need for participation in periodic elections. But many have argued that participatory opportunities should go beyond elections, including channels for citizen involvement in between elections as well. In Dahl's view, for example, elections should be supplemented by additional participatory opportunities for public participation in setting the political agenda and for discussing the pros and cons of different political choices regarding issues on the agenda (Dahl 1989: 109). For both normative as well as instrumental reasons, this same perspective is found in the work of many

8 There is also another form of accountability that refers to the accountability of appointed government officials to their elected political principals. Although an important aspect of democratic accountability, an analysis of this second type of accountability is beyond the scope of our research. A satisfactory analysis of the politico-administrative relations in local governments (including possible size effects) would require a separate study with a completely different research design. 
participatory democratic theorists (see e.g. Barber 1984; Pateman 1970). Among the four countries given closer consideration in the present work, Switzerland extends this perspective even further by maintaining several forms of direct democracy which offer citizens alternative means for influencing the political agenda and deciding important political issues independent of the election cycle.

The need for widespread participation is by no means universally acknowledged however. Especially in the aftermath of the collapse of democratic regimes in the 1930s, a number of democratic theorists have taken the position that the political participation of ordinary citizens is perhaps best enjoyed in moderation' (Jackman 1987: 419). This position is endorsed by theorists like Morris Jones (1954), Almond and Verba (1963) and Huntington (1974). Stoker rather bluntly summarizes the implications of this position as one in which 'citizens should vote, choose their government and then get out of the way' (Stoker 2006: 152). But in contemporary political theory views on citizen participation have become more favourable. Widespread participation is now often considered as desirable for at least two reasons. For one thing it minimizes the risk that the voice of the participants misrepresents the needs and the demands of the citizenry at large (see e.g. Rosenstone \& Hansen 1993; Verba et al. 1995). ${ }^{9}$ For another, it is desirable from the perspective of the norm of political equality. The larger the share of the citizenry that participates, the closer a polity comes to the ultimately unachievable ideal of political equality where each citizen has an equal influence on public decisions (see Dahl 1989).

In order to realize its potentially benign democratic effects for the political system's responsiveness and accountability, participation needs to be both responsible and competent. Here responsible behaviour implies that citizens are active, but are so within a legally defined political opportunity structure. On the basis of the prescription of responsible activism, citizens should therefore make extensive use of legitimate forms of both electoral and non-electoral participation.

Yet acting responsibly is not enough: according to Dahl and Tufte, citizens should also act competently. The norm of political competence has a number of implications. Most important is that citizens should take an interest in political affairs and be capable of forming an informed opinion about political issues (Dahl 1985: 59-60; Denters et al. 2007a; Putnam et al. 1993: 87; Rose \& Pettersen 1997). To form an informed

9 On these grounds Lijphart (1997), for example, has argued in favour of the introduction of compulsory voting. 
opinion presumes that citizens are well informed about government and its responsibilities. This political knowledge may also be an important factor that impacts upon whether voters cast an informed ballot in elections. In addition to interest and actual knowledge, however, a sense of subjective political competence is critical. Judged by the democratic ideal of political equality, a situation where large sections of the population feel incompetent to understand and act effectively in political matters is unacceptable. This is especially the case since such a widespread lack of political competence is likely to result in relatively limited political participation.

The notion of democratic government also has implications for the conduct of political officials and for the outputs of the governmental system. For the sake of democratic legitimacy, political officeholders should be trusted to act in accordance with the democratic norm of responsiveness. This form of democratic confidence not only implies that government and political officeholders are open and accessible to public demands. It also implies that they should be of high integrity, not readily distracted from acting in the public interest by personal or special interests, and that they should be competent to register and act upon collective needs and demands. Furthermore, with regard to outputs, a democratic system of government should be able to perform adequately in order to secure citizen satisfaction with public policies, public services and facilities. ${ }^{10}$

Taken together, these expectations about the relevant dimensions and indicators of democracy associated with them can be summarized as shown in Table 1.1. In subsequent chapters of this book each of the indicators is operationalized and subject to closer empirical investigation.

10 This idea is actually close to Scharpf's notion of output legitimacy and Dahl and Tufte's concept of system capacity. Although both Scharpf (1999) and Dahl and Tufte (1973) refer to the extent to which policies actually represent effective solutions to the problems of the governed from the perspective of democratic quality, the satisfaction of citizens with policies, services and facilities may be seen as an important indicator of democratic legitimacy, where legitimacy is seen as a micro-political orientation (cf. Wheatherford 1992). 


\section{Table 1.1 Dimensions and indicators of democracy}

\begin{tabular}{ll}
\hline Dimension & Indicators \\
\hline Active participation & $\begin{array}{l}\text { - Electoral participation (turnout and informed voting) } \\
\text { - Non-electoral participation }\end{array}$ \\
Citizen competence & $\begin{array}{l}\text { - Political interest } \\
\text { - Political knowledge } \\
\text { Subjective political competence }\end{array}$ \\
Political confidence & $\begin{array}{l}\text { - Citizens' perceptions of government responsiveness, } \\
\text { integrity and competence }\end{array}$ \\
Citizen satisfaction & $\begin{array}{l}\text { - Citizens' satisfaction with government performance } \\
\text { (policies, public services and facilities) }\end{array}$ \\
&
\end{tabular}

\section{THINKING ABOUT SIZE EFFECTS: AN ANALYTICAL FRAMEWORK}

As noted above, Aristotle incorrectly assumed that it would be relatively easy to ascertain the optimum size of local governments. But one of the major barriers in efforts to do so has been the lack of firm empirical knowledge about the effects of size. In this book we seek to fill at least part of this gap in empirical knowledge by answering the question, what is the effect of population size on the democratic quality of municipal government? In answering this question one of the challenges we face is that there are a variety of theoretically plausible claims and counterclaims regarding the effects of size on various aspects of democratic quality. Dahl and Tufte, for example, argue that size may have both a positive and a negative effect on the responsiveness of leaders. Rather than being contradictory statements, both claims may be true at the same time. This is so because size may have a positive indirect effect through one intervening variable while at the same time having a negative indirect effect through another. To illustrate this situation Dahl and Tufte (1973: 13-15) argue that because small democracies offer citizens more opportunities to participate effectively in making local decisions, leaders in small democracies are likely to be more responsive to citizen views than local leaders in large democracies. But at the same time they argue that because large democracies are more likely to be politically competitive than smaller ones, leaders in larger democracies are likely to be more 
responsive to the views of citizens than those in small democracies. ${ }^{11}$ Dahl and Tufte also observe that these and similar 'claims and counterclaims are perfectly consistent with one another' (Dahl \& Tufte 1973: 15). As Figure 1.1 demonstrates, this may be true because size has an impact on the dependent variable (the responsiveness of leaders in this case) through two intervening factors: (i) opportunities for effective participation; and (ii) the likelihood of keen political competition.

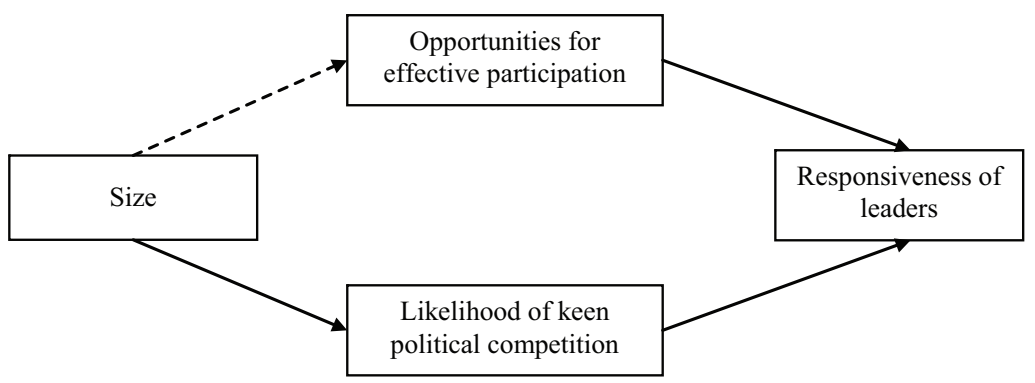

Legend $\longrightarrow$ predicted positive effect $(+)$

Source: Simplified illustration based on Dahl and Tufte (1973: 13-15 and 89-109).

Figure 1.1 An example of claims regarding alternative (and consistent) indirect effects of population size for an indicator of local democracy

This example illustrates why it is important to map the causal mechanisms that link size to our indicators of local democracy with care. Such causal mechanisms will occasionally imply direct effects of size, but will also frequently imply indirect effects in which size effects are transmitted through one or more intervening variables (such as those found in Figure 1.1). In subsequent chapters we frequently encounter more or less complicated sequences of this sort linking size to the political orientations and actions discussed in the previous section.

11 Our purpose here is merely illustrative. Hence we do not reconstruct the full complexity of Dahl and Tufte's argument, and have drawn upon some arguments which they only developed more fully in later chapters within their book (see Chapter 6 in Dahl \& Tufte 1973). 
In constructing theoretical arguments about the possible impact of size on the character of local democracy there is a vast body of literature to draw upon. To deal with the complexity encountered, it is useful to have a framework to organize our thinking. Ideally such a framework should satisfy two criteria: first, it should be sufficiently abstract and general so as to serve as a tool for integrating different theoretical approaches, and second, it should help to understand sequences of events (causal chains) that lead from the key explanatory factor - size - to democratically relevant political orientations and political behaviours. The 'funnel of causality' developed by Campbell et al. (1960) provided such a tool for these purposes (see Figure 1.2). Although the 'funnel' was initially developed for the analysis of voting behaviour, its basic logic is also applicable to the explanation of other forms of political choice. The 'funnel' implies that individual political behaviour is explained by individual political orientations and that in turn these political orientations are the effect of causally more remote factors such as a person's social orientations (e.g. social trust), personal background characteristics (e.g. gender), and characteristics of the broader context in which an individual is situated (e.g. municipal size). In this book the 'funnel' is therefore used as a heuristic device for charting the factors that explain individual political orientations and behaviour.

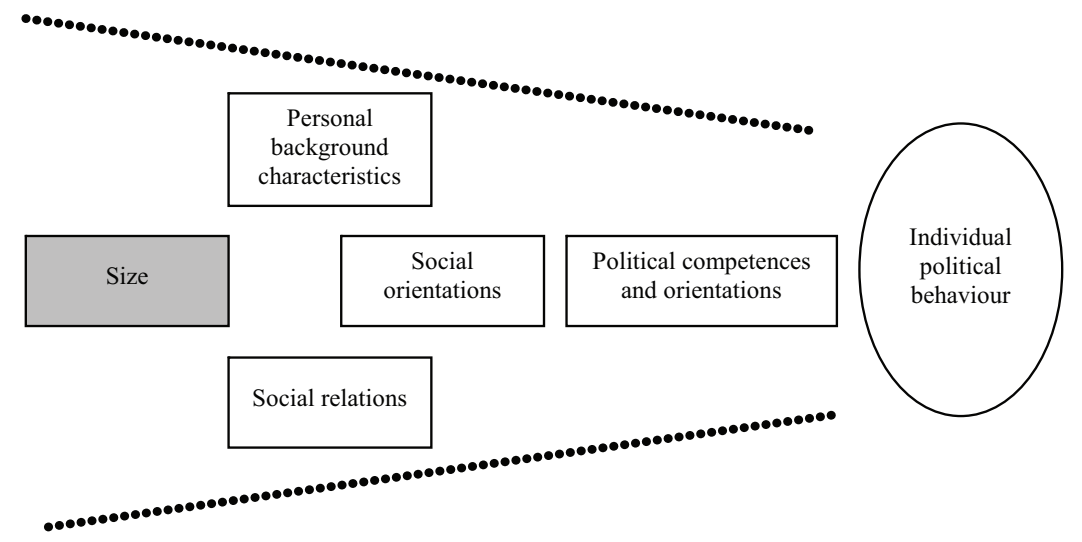

Figure 1.2 A funnel of causality for investigating the effects of population size on the quality of local democracy

The starting point for this framework is the general presumption that political behaviour is a 'function of the individual's own "definition of the situation"' (Campbell et al. 1960: 27). Arguably what is most critical 
in defining the situation, and hence stands in closest direct antecedent proximity to political behaviour, are individual political competencies and orientations, as indicated by their placement immediately to the left of political behaviour in Figure 1.2. But such competencies and orientations, which are intrinsically important from a democratic perspective, are themselves influenced by an interplay of various other factors, some of which are personal socio-economic background characteristics (e.g. age, education, occupation, etc.), while others are individual social relations (integration into a neighbourhood, associational involvement, etc.) and more general social orientations held by individuals (identification with diverse social communities, interpersonal trust, etc.). And the size of local government may in one way or another, either directly or indirectly, be related to and have an impact on all of these variables.

Some of the political orientations in our analysis, therefore, serve a dual purpose. An individual's subjective political competence, for example, is on the one hand a political orientation that is intrinsically important from a democratic perspective. On the other hand, as we will see in Chapters 10-12, it is also relevant because it is plausibly a factor that might help us understand the sequence of events leading from size to various forms of local political participation. Factors like political interest, political knowledge and political confidence may likewise have a dual status and role - that is, they are relevant dependent variables in their own right, but may also serve as intervening variables in a sequence of causal events or phenomena which in the end affect other relevant dependent variables which are found further to the right in our analytical framework (the funnel of causality).

\section{SIZE AND LOCAL DEMOCRACY - LILLIPUT OR BROBDINGNAG?}

Discussion of our analytical framework thus far has been cast largely in terms of an individual, micro-level theory of political action. This book, however, is about the democratic effects of population size. We therefore have to link the population size of local government units (and perhaps also other relevant community characteristics) to considerations relating to various factors in the funnel of causality. In the remainder of this chapter we outline the basic theoretical answers to our central research question in which links are established between size and people's social relations, social orientations, political competence and orientations and political participation. In doing so, the theoretical arguments on which answers to our central research question are based can be placed into two 
principal groups. ${ }^{12}$ The first line of argument implies that size is likely to have negative effects on the quality of local democracy. This line of argument essentially highlights the advantages of small-scale government. Inspired by the first book of Jonathan Swift's famous satiric novel Gulliver's Travels (1726), we will refer to this line of reasoning as the Lilliput argument. In Book I of this novel Lilliput is the name of a fictional country where the novel's main character, the ship's doctor, Lemuel Gulliver, is washed ashore after a shipwreck. The country is inhabited by tiny - 15 centimetres tall - citizens, who capture Gulliver. In eight lively chapters Swift tells us about the exploits of Gulliver in the miniature Empire of Lilliput with its towns that look like painted scenes of cities on the stage setting of a theatre.

The second group of arguments essentially implies just the opposite: the size of municipalities is likely to have positive effects on the quality of local democracy. Big is beautiful! Again Jonathan Swift's novel offers us an imaginative label to characterize this narrative. In Book II, much less widely known than Book I, Gulliver, 'having been condemned, by nature and fortune, to an active and restless life' (Swift 1726: 97), following his safe return from his eventful journey to Lilliput, sets out on a new voyage. When he is unfortunately separated from his companions, Gulliver finds himself stuck in this case in the Kingdom of Brobdingnag, where everything is of colossal size: men are as tall as churches and rats are the size of dogs. After having experienced the sensation of being a giant amongst the Lilliputians, Gulliver is now placed in the role of the dwarf amidst the gigantic Brobdingnagians. Notwithstanding their intimidating physiognomy, Gulliver soon comes to realize that the Brobdingnagians are as kind-hearted, generous and freedom-loving as they are gigantic. It seems quite appropriate, therefore, to refer to advocates of large-scale local government as putting forth the Brobdingnag argument.

In addition to these two lines of argument, there is also a third line of argument that implies that size is not likely to have any effect - either positive or negative - on the quality of local democracy. This third line of argument is discussed in the concluding part of this section.

12 The distinction presented here draws upon, among others, the work of Elinor Ostrom (1972) who differentiated between Reform Theory on the one hand and Public Choice Theory on the other. Ostrom and Parks (1999) even referred to Gulliver's Travels and Lilliput (as a contrast to Gargantua) in discussing issues of scale and governance in metropolitan areas. 


\section{Scenario I - Lovely Lilliput}

Since the publication of Ferdinand Tönnies' book Gemeinschaft und Gesellschaft in 1887, many sociologists have studied the implications of urbanization and the associated changes in the scale of towns and cities. In Louis Wirth's view, for example, a city is 'a relatively large, dense, and permanent settlement of socially heterogeneous individuals' (Wirth 1938: 8). On the basis of this definition Wirth develops a theory of urbanism in which he derives a number of hypotheses relating to the social effects of increasing population size, density and heterogeneity. For our present purposes, hypotheses pertaining to the effects of population size are of course the most relevant. Wirth and other sociologists have in this regard emphasized that increases in the size of communities are likely to affect the nature of community life - to wit: '[an] increase in the number of inhabitants of a community beyond a few hundreds is bound to limit the possibility of each member of the community knowing all the others personally' and this implies that 'in relation to the number of people whom they [i.e. urban residents] see and with whom they rub elbows in the course of daily life, they know a smaller proportion, and of these they have less intensive knowledge' (Wirth 1938: 11-12). Increasing size, in short, is likely to change the character of people's social relations - for example in terms of a decline of neighbourliness - and their social orientations - for example in terms of declining community identification, an increasing sense of anomie and social distrust.

The work of Wirth has been highly influential. Many students of urban society and urban politics have followed in his footsteps (see e.g. Bell \& Newby 1971; Lyon 1989). His sombre hypotheses about the impact of increasing size on social cohesion have been criticized, but even so similar arguments have often reappeared in the political science literature about the potential democratic effects of the population size of government. Scholars like Dahl and Tufte (1973: 41-65), Verba and Nie (1972: 229-47), Verba et al. (1978: 269-85) and Oliver (2000, 2001) have all formulated and tested the so-called decline of community model. This model posits that increases in size will have negative effects on social cohesion, and that, because of these negative effects, increases in size will also have a negative impact on people's political orientations (e.g. political interest) and their willingness to engage in political action, both in terms of electoral and non-electoral political participation. In a similar vein, Robert Putnam has also claimed that increasing urbanization has been one of the sources that contributed to the decline of social capital and of civic engagement in the USA (Putnam 2000: 204-15). 
This pessimism regarding the negative effects of increases in size on the vibrancy of civic and political life is shared by a number of public choice theorists. Whereas sociologists and like-minded political scientists emphasize the negative effects of increasing scale on the nature of community life, Public Choice Theory points to a number of disadvantages of increasing population size for the organization and performance of local governments. Viewed from this angle, local government is conceived of as a 'public service industry' (Oakerson 1999) that provides and produces collective and quasi-collective goods for a particular public. A public is defined as all those who are affected by the provision of such a good. The approach is based on the normative principle of the sovereignty of this public and therefore focuses on a key aspect of democratic performance - namely the effects of institutional arrangements on the capacity of governments to be responsive to citizen demands for such public goods and services (Ostrom 1989). ${ }^{13}$

From this perspective, the responsiveness of local government is determined by two sets of considerations: first, the capacity and willingness of local politicians and officers to heed public demands, and second, the degree to which local political opportunity structures provide accessible and effective channels that citizens are able to use to express their preferences and to signal their approval or disapproval (Ostrom 1989: 57-8). Large-scale public organizations have considerable disadvantages on both counts. Thus, with respect to the capacity and willingness of local government personnel to heed public demands, the political economy approach argues that increasing the scale of government necessarily implies a growing reliance on hierarchy and bureaucratic organizational structures. Building on analyses by Tullock (1965) and Downs (1967), public choice theorists suggest that a large-scale bureaucracy will tend to become uncontrollable and increasingly indiscriminating in its response to diverse demands [...] and fail to proportion supply to demand' (Ostrom 1989: 56). This is even more problematic because the diversity of public demands associated with large-scale publics makes the task of proportioning supply to the public's demands much more

13 The effects of size on the cost efficiency of producing particular collective goods, which has also been the subject of economic analysis, is largely ignored in this book. We concentrate instead on the democratically more salient effects of size on the capacity of local governments to be responsive to public demands. Analyses of economies of scale typically show that the relation between size and cost efficiency varies from one type of service to another. For surveys of this literature see Bennett (1980); Boyne (1995); Hirsch (1968); Houlberg (1995, 2000); and Martins (1995). 
exacting than in smaller units. ${ }^{14}$ Such effects are likely to be reflected in people's political perceptions - in particular their satisfaction with municipal performance and perceptions of the responsiveness of local government.

As for the actual use of participatory channels, the political economy approach points to factors associated with the costs of participation, the benefits of participation and the perceived responsiveness of local government. Based on reasoning developed with respect to the calculus of voting (Downs 1957), Dahl and Tufte (1973: 41-4) argue that the effectiveness of citizens in making themselves heard in politics is likely to decrease with increasing size. Moreover, the participatory costs for direct forms of political engagement in large municipalities will also tend to be higher, a situation resulting from reduced opportunities to contact elected officials. In addition to increased social diversity, the accumulation of problems and the attitudinal variety of political orientations represented in the political arena lead to an increasing complexity in the political process. This complexity in turn implies higher information costs that are likely to have a negative effect on levels of local political knowledge. Bureaucratization and relatively limited opportunities for direct political influence may also feed public doubts about local government's responsiveness.

\section{Scenario II - Beautiful Brobdingnag}

On the other side of the debate on size and democracy, a variety of arguments are advanced to support claims in favour of the large scale. In reaction to Wirth's sombre account of the negative effects of increasing size on civic life, a number of sociologists have argued that Wirth may have been too pessimistic. The most prominent critic of Wirth has been Claude Fischer. The main thesis in Fischer's perspective is that the decline of traditional communities will be compensated by the development of new, more differentiated patterns of social integration (see Fischer 1995). The basic assumption underlying this argument is that size and an increasing diversity in the personal backgrounds of city-dwellers are likely to be accompanied by increasing associational diversity. In

14 The complementarity of the sociological and the political economy approach is underlined by the fact that Wirth makes a similar argument: 'When large numbers have to make common use of facilities and institutions, an arrangement must be made to adjust the facilities and institutions to the needs of the average person rather than to those of particular individuals' (Wirth 1938: 18). 
political science Dahl and Tufte made a similar argument. They argue that with increasing size, the number and the diversity of social and political organizations will increase (Dahl \& Tufte 1973: 30-40, 89-109).

Following Dahl and Tufte's line of argument, Baglioni and his associates (2007) have analysed the effects of size on the structure of organizational life - the so-called associational ecology of Warren (2001) or civic fauna of Rae (2003). ${ }^{15}$ These scholars hypothesize that the larger the size of a jurisdiction and the higher the number of potential members of a particular latent group (e.g. potential members of a football club), the higher the number of organizations in that particular 'associational niche' (football clubs). Moreover, in keeping with Dahl and Tufte (1973: 13-14), they also argue that large-scale political units are likely to exhibit more social diversity in terms of people's beliefs, values, goals, interests and social and economic characteristics. Since the numeric logic underlying the formation of football clubs also pertains to other latent groups, the combined effects of this 'logic' and social diversity will not only provide a further increase in the jurisdiction's number or density of organizations, but will also result in an increased diversity of the associational ecology (Baglioni et al. 2007).

On the basis of the same line of reasoning Verba and Nie (1972: 229-47; see also Verba et al. 1978) formulated their mobilization model. This model implies that a more extensive and diverse associational ecology is likely to result in a more differentiated and competitive democratic system. In such a system citizens are more likely to become interested in and knowledgeable about politics (cf. Dahl \& Tufte 1973: 44; Verba \& Nie 1972: 229-47; Verba et al. 1978: 270). In addition, it is also argued that such a more differentiated and competitive political system is likely to increase the responsiveness of the political system to the public's policy preferences (cf. Denters \& Geurts 1998a, 1998d; Hill \& Anderson 1995: 926; Mouritzen 1989: 663; Verba \& Nie 1972: 309-18).

The increasing size of human settlements also leads to the advent of highly specialized, professionalized public sector institutions for health care, social work and cultural advancement (Wirth 1938: 21-2). Many such institutions are organized as part of local government. Wirth does not explicitly discuss the implications of the extension of local government's responsibilities, but US Reform Theorists and kindred spirits in

15 In local politics Newton (1976), Maloney et al. (2000) and Smith et al. (2004) have conducted empirical studies of the civic fauna of Birmingham in England. 
Europe have indicated that the expansion of tasks and the need to meet the demands of citizens will require an increase in the functional capacity of local governments by means of an expansion of their bureaucracies (see e.g. Ostrom 1972: 476). In the European context a concern with the effectiveness and efficiency of local government in delivering public services, especially in north-western Europe, has often resulted in drastic reductions in the number of municipalities and an increase in their population size (Baldersheim \& Rose 2010b: 6; Martins 1995; Sharpe 1988: 95-100). Implicitly or explicitly the motivations for such reforms are based on the assumption that a high degree of effectiveness and efficiency is contingent upon a high degree of specialization and professionalization of local government and that only large-scale systems have the resources to afford such high levels of functional differentiation (see Denters et al. 1990; John 2010).

In the footsteps of Ostrom, efforts have been made to develop the often implicit notions underlying these reforms into a Reform Theory consisting of a set of explicit propositions about the possible benign effects of increases in the population size of local government on the functional capacity of municipalities (see e.g. Denters \& Geurts 1998d; Mouritzen 1989). The argument of Reform Theory is based on the proposition that an increase in the size of local governmental units will lead to a more fully developed local bureaucracy (Ostrom 1972: 479). It is hypothesized that such bureaucratization will improve the effectiveness of local government (Denters \& Geurts 1998d; Ostrom 1972: 479). ${ }^{16}$ This latter proposition is in line with the bureaucratic theory of Max Weber who pointed to the fact that such bureaucratic organization is superior 'in precision, in stability, in the stringency of its discipline, and in its reliability' (Weber 1978: 223; Weber 1980 [1921]: 128). Weber was by no means alone in emphasizing the importance of bureaucratization as a condition for social and economic modernization. In a similar vein, US public administration scholarship in the early decades of the previous century (and long after) was convinced that the realization of a good society would require a centralized, hierarchically structured administrative apparatus and a body of competent, professional administrators that would secure an efficient implementation of political decisions (Ostrom 1989: 20-41; Waldo 1984: 49-59; Wilson 1996).

16 Sometimes it is also argued that increasing size will allow for economies of scale. As already indicated, we do not deal with any possible size effects related to this topic. 
In this book we are not in a position to assess the empirical validity of these implications of Reform Theory. If the assumptions underlying the basic line of reasoning are correct, however, it might be expected that increasing the size of local government units would have a positive effect on citizens' ideas about, for example, the salience of the municipality, local political interest and public satisfaction with local government performance (Denters \& Geurts 1998d; Mouritzen 1989). Presumably such effects on people's political orientations may in turn have a bearing upon the likelihood of voting participation and other forms of organized political participation.

\section{Size and Democracy - A Third Alternative?}

In considering relationships between size and a number of democratically relevant political attitudes and political behaviours, it is imperative that we keep in mind that such relationships could be the result of two basic mechanisms. They may be the result of causal effects whereby size either directly or indirectly through other intervening variables has an impact on one or more of our primary dependent variables - that is, democratically relevant political attitudes and political behaviours. The two models outlined in the previous sections are built on the basis of just such theoretically plausible causal effects. Yet there is another possibility. This possibility is one that arises in as much as size co-varies with the socio-demographic composition of municipalities (e.g. in terms of level of education). Under such circumstances the association of size with measures of democracy (e.g. in terms of the level of political knowledge) may be exclusively the result of differences in the composition of the local population, because higher education tends to go hand-in-hand with a higher level of political knowledge. If this is the case, then the relationship between municipal size and quality of local democracy (e.g. level of political knowledge) will disappear after appropriate statistical controls for compositional variables (e.g. level of formal education). ${ }^{17}$

In urban sociology this position has been taken by Gans (1962). In his analysis of differences between cities and suburbs he concludes that 'differences in ways of life between the two types of settlements have been overestimated' (1962: 635) and that many of these differences can be better explained by looking at the differences in their populations (especially differences in social class and life-cycle stage (1962: 640)):

17 This possibility and the means we use to deal with it are addressed in great detail in Chapter 2. 
'Thus, in the inner city, the unmarried and childless live as they do, detached from neighbourhood, because of their life-cycle stage; the cosmopolites, because of a combination of life-cycle stage and a distinctive but class-based subculture' (Gans 1962: 640, emphasis added). Like Gans, Verba and his associates recognize the need to take possible compositional effects into consideration:

Small towns and big cities are different sociopolitical environments; they are also inhabited by different kinds of people. [...] In order to isolate the effect on participation of the sociopolitical environment provided by the community, we must separate out the effects of the socioeconomic characteristics of the individual living in the communities. (Verba et al. 1978: 273)

In analysing the possible effects of size it is therefore necessary to take the effects of potentially confounding factors into account. ${ }^{18}$

\section{ORGANIZATION OF THE BOOK}

In the following chapter we discuss how we have chosen to proceed with our investigation of these different empirical alternatives. The chapter begins with a brief review of shortcomings found in previous research and then presents our research design, how we have dealt with a variety of issues encountered, and how we present our research findings. After this, Chapter 3 provides a description of the systems of local government in the four countries selected for research, the intent being to give readers some insight into the research context of our study.

Chapters 4 to 12 are then devoted to more detailed theoretical explications relating to how size may have some impact on different dimensions of democracy and the indicators used to tap these dimensions. The ordering of the chapters follows the logic of the funnel of causality introduced above. In Part II we begin with two chapters dealing with the social and political environment of local government. Chapter 4 focuses on the municipality as an arena of social integration, whereas Chapter 5 deals with policy challenges as these are linked to municipalities of different size.

Part III of the book is devoted to various cognitive and evaluative aspects of democracy, aspects which are often seen as having a bearing on whether or not citizens will become more actively involved in politics.

18 For further comments on 'compositional effects' see the next chapter. 
Chapter 6 delves into local political interest and local political knowledge, whereas Chapter 7 offers a closer look at aspects of individual subjective political competence. In the subsequent two chapters the focus is on how citizens view their municipal political environment. In Chapter 8 the question is whether municipal size is of importance for the confidence residents have in their (elected) political leaders. Then in Chapter 9 the issue is whether size is of any relevance for the satisfaction (or lack thereof) which residents may have for the performance of local government.

With these findings in mind, Part IV of the book turns to participatory aspects of local democracy. Chapter 10 takes up two considerations relating to local electoral behaviour: first, the likelihood that residents will in fact go to the polls and vote is examined, and then, if they do so, whether their votes will reflect a distinct local (as opposed to national) political character. In Chapter 11 three different types of non-electoral behaviour are taken up - political party activity, community action and local contacting - and subjected to closer investigation with respect to what relevance, if any, municipal size may have for whether or not residents undertake these activities. Finally, in order to gain a greater understanding of how size may impact on forms of direct democratic participation, Chapter 12 is devoted to an analysis of conditions found in Switzerland, where referenda and decision making by means of local assemblies are important components of local democracy.

The last two chapters in the book (Chapters 13 and 14) summarize the findings presented in Chapters 4 to 12 and present a conclusion that draws on four different types of evidence found in our results. The final chapter also identifies theoretical implications of the findings and in addition points to democratic dilemmas which remain to be resolved. 